\title{
Dynamics of nutrients, total organic carbon, prokaryotes and viruses in onboard incubations of cold-water corals
}

\author{
C. Maier ${ }^{1,2,3}$, A. de Kluijver ${ }^{3}$, M. Agis ${ }^{1,2}$, C. P. D. Brussaard ${ }^{3}$, F. C. van Duyl ${ }^{3}$, and M. G. Weinbauer ${ }^{1,2}$ \\ ${ }^{1}$ INSU-CNRS, Laboratoire d'Océanographie de Villefranche, UMR 7093, B.P. 28, 06234 Villefranche-sur-Mer Cedex, France \\ ${ }^{2}$ Université Pierre et Marie-Curie-Paris, Laboratoire d'Océanographie de Villefranche, UMR 7093, \\ 06230 Villefranche-sur-mer, France \\ ${ }^{3}$ Department of Biological Oceanography, Royal Netherlands Institute for Sea Research (NIOZ), P.O. Box 59, \\ 1790 AB Den Burg, Texel, The Netherlands
}

Received: 22 March 2011 - Published in Biogeosciences Discuss.: 14 April 2011

Revised: 17 August 2011 - Accepted: 29 August 2011 - Published: 14 September 2011

\begin{abstract}
The potential influence of the cold-water corals (CWCs) Lophelia pertusa and Madrepora oculata on the dynamics of inorganic nutrient and total organic carbon (TOC) concentrations and the abundances of prokaryotes and viruses in bottom water was assessed in onboard incubation experiments. Ammonium, nitrite, dissolved inorganic nitrogen (DIN), dissolved inorganic phosphorus (DIP) and TOC concentrations and N:P ratios were typically higher in incubation water with corals than in controls, whereas nitrate concentrations did not reveal a clear trend. $\mathrm{Mu}-$ cus release (normalized to coral surface) was estimated by the net increase rate of TOC concentrations and averaged $23 \pm 6 \mathrm{mg} \mathrm{C} \mathrm{m}^{-2} \mathrm{~h}^{-1}$ for L. pertusa and $21 \pm 8 \mathrm{mg} \mathrm{C}$ $\mathrm{m}^{-2} \mathrm{~h}^{-1}$ for $M$. oculata. Prokaryotic and viral abundance and turnover rates were typically stimulated in incubation water with corals. This estimated prokaryotic stimulation averaged $6.0 \pm 3.0 \times 10^{9}$ cells $\mathrm{m}^{-2} \mathrm{~h}^{-1}$ for $L$. pertusa and $8.4 \pm 2.9 \times 10^{9}$ cells $\mathrm{m}^{-2} \mathrm{~h}^{-1}$ for $M$. oculata, whereas the estimated viral stimulation averaged $15.6 \pm 12.7 \times 10^{9}$ particles $\mathrm{m}^{-2} \mathrm{~h}^{-1}$ for L. pertusa and $4.3 \pm 0.4 \times 10^{9}$ particles $\mathrm{m}^{-2} \mathrm{~h}^{-1}$ M. oculata. Our data suggest that prokaryotes and viruses are released from corals and that nutrient and mucus release enhanced prokaryotic and viral production. The result of this stimulation could be a fuelling of bottom water in CWC reefs with nutrients and organic matter and consequently an enhancement of microbe-mediated processes.
\end{abstract}

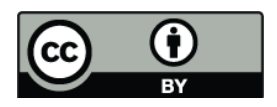

Correspondence to: M. G. Weinbauer (wein@obs-vlfr.fr)

\section{Introduction}

The distribution of corals ranges from shallow waters to the deep abyssal plains. Coral reefs or bioherms do not only occur in tropical surface waters but also in deep and cold waters (Roberts et al., 2006). Lophelia pertusa and Madrepora oculata are important species as main frame-builders of these cold-water coral (CWC) ecosystems, which sustain a large biodiversity and biomass (Rogers, 1999). CWC reefs seem to thrive in areas of elevated hard substrata and enhanced water flow, which could prevent sedimentation and provide the necessary food sources (Rogers, 1999; Roberts et al., 2006; Mortensen et al., 2001; Davies et al., 2009).

There is evidence that CWC reefs preferentially remove nitrogen and are hotspots of remineralization activity in the ocean (Lavaleye et al., 2009). Moreover, it has been demonstrated that dissolved carbon fixation by sponge-microbe consortia is high in this habitat (van Duyl et al., 2008). Corals (including CWC species such as L. pertusa) can also release significant amounts of mucus (e.g. Ducklow and Mitchell, 1979b; Herndl and Velimirov, 1986; Wild et al., 2008), which has been shown to function as an energy carrier and particle trap in tropical reef systems (Wild et al., 2004). This recycling loop supports the growth of benthic organisms and consequently reduces losses of energy and matter from the ecosystem (Wild et al., 2004). It has also been shown that $L$. pertusa and $M$. oculata release mucus, which stimulates oxygen consumption rates of microorganisms (Wild et al., 2008, 2009). It is known from studies in tropical areas that mucus and nutrient release into the interstitial space of corals can enhance microbial abundance (Schiller and Herndl, 1989; Ferrier-Pagès et al., 2000). Coral mucus harbours a high density of prokaryotes (e.g. Ducklow and

Published by Copernicus Publications on behalf of the European Geosciences Union. 


\section{Live corals}
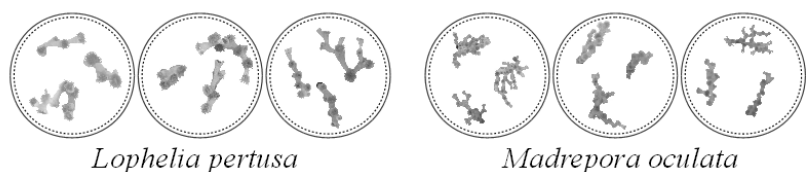

Controls

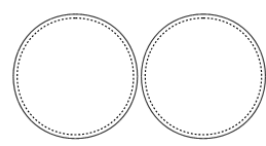

only seawater

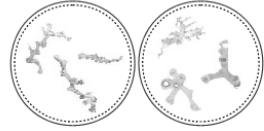

bleached skeletons

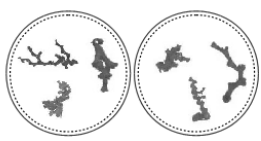

skeletons with biofilm

Fig. 1. Experimental set-up.

Mitchell, 1979a; Koren and Rosenberg, 2006). A first insight into the bacterial community structure is available for $L$. pertusa (Yakimov et al., 2006; Kellogg et al., 2009; Neulinger et al., 2008; Schöttner et al., 2009), M. oculata (Hansson et al., 2009) and CWC sediments (Jensen et al., 2008a, b).

Viral abundances have not been often quantified in coral reef systems (Paul et al., 1993; Dinsdale et al., 2008; Patten et al., 2008b; Weinbauer et al., 2010). It is known that reef corals and zooxanthellae can be infected by viruses (e.g. Wilson et al., 2005; Danovaro et al., 2008) and lytic phages of coral pathogens have been isolated (Efrony et al., 2007). The morphological diversity of viruses in coral mucus and in the holobiont is high (Davy and Patten, 2007; Patten et al., 2008a) and a high diversity was also shown by viral metagenomics of the holobiont (Marhaver et al., 2008). There is also some in situ evidence that viral abundance increases close to corals (Patten et al., 2006; Seymour et al., 2005). To the best of our knowledge, nothing has been published on viruses in CWC ecosystems.

The aim of this study was to assess potential interactions of cold-water corals with some central components of the microbial food web in the dark ocean, i.e. nutrients, organic carbon, prokaryotes and viruses. The potential role of the cold-water corals $L$. pertusa and $M$. oculata for the dynamics of inorganic nutrients and total organic carbon (TOC) was addressed in on-board incubations. Moreover, it was investigated, whether prokaryotes and viruses are released from the corals. Finally, an attempt was made to quantify mucus release and the stimulation of prokaryotic and viral production in incubations water with cold-water corals.

\section{Material and methods}

\subsection{Study site and sampling}

The sampling site was at the CWC reef located on the southeastern Rockall Bank at the Clan mounds $\left(55.444^{\circ} \mathrm{N}\right.$ to $55.445^{\circ} \mathrm{N},-16.072^{\circ} \mathrm{E}$ to $-16.975^{\circ} \mathrm{E}$ ) and Haas mounds $\left(55.491^{\circ} \mathrm{N}\right.$ to $55.501^{\circ} \mathrm{N},-15.788^{\circ} \mathrm{E}$ to $\left.-15.801^{\circ} \mathrm{E}\right)$. The

two mounds are ca. $20 \mathrm{~km}$ apart. Sampling was performed during the BIOSYS/HERMES cruise of the RV Pelagia between 21 June and 21 July 2005 (http://www.nioz.nl/ public/dmg/rpt/crs/64pe263.pdf). Specimen of L. pertusa and $M$. oculata were collected from $560-780 \mathrm{~m}$ using boxcore samplers (for more details of the study site and sampling see van Duyl et al., 2008). Corals used in experiments originated from 12 casts. This increases the probability that the corals differed in clonal structure and physiological status thus, making them more representative for the coral ecosystem.

\subsection{Keeping of corals}

Onboard, small branches of $L$. pertusa ( $9 \pm 4$ polyps) and $M$. oculata ( $32 \pm 16$ polyps) without epibionts were taken mainly from large colonies in boxcores with little sediment content. They were handled with forceps and if necessary briefly exposed to air for gluing onto Petri dishes using underwater Epoxy ${ }^{\circledR}$ and for photographing. These microcolonies were kept in acid-cleaned and seawater rinsed 201 plastic tanks in bottom seawater. Tanks were kept in the dark at ca. in situ temperature $\left(9^{\circ} \mathrm{C}\right)$. Bottom water $(580-770 \mathrm{~m})$ for keeping corals was sampled with a 10001 water box (see van Duyl et al., 2008). One third of the seawater was replaced every third day with freshly collected bottom water without exposing corals to air. A water flow was generated by small submerged aquarium pumps with a capacity of $250 \mathrm{l}^{-1} \mathrm{~h}^{-1}$. Micro-colonies were feed with freshly hatched Artemia. The micro-colonies were kept for 2-7 days for acclimation before they were used in experiments.

\subsection{Incubations to assess the dynamics of nutrients, organic carbon and microorganism}

Per replicate, three micro-colonies of $L$. pertusa or $M$. oculata were placed into an acid cleaned hardplastic jar filled with 31 of sea water (see Fig. 1 for a summary of the experimental approach). For coral treatments, experiments were performed in triplicates. Corals appeared healthy with extended polyps and tentacles during the experiment.

Three types of controls were run in duplicates each: (1) seawater without corals, (2) seawater with dead microcolonies (containing biofilms) and (3) seawater with dead micro-colonies which were bleached (containing no or almost no biofilm). To remove the biofilm of dead corals, the skeletons were soaked in house-hold bleach overnight, thoroughly rinsed with a stronger water ray and then in MilliQ and dried in an oven at $60^{\circ} \mathrm{C}$ for at least $24 \mathrm{~h}$ prior to experiments. In the dead coral controls, one replicate consisted of two colonies of $L$. pertusa and one colony of $M$. oculata, the other of one colony of $L$. pertusa and two colonies of M. oculata. Thus, the same controls were used for the two coral species. The restriction to duplicates for the different types of controls and the mixture of dead colonies was done 
because of space and handling limitations in the temperaturecontrolled walk-in containers. All incubations were kept at in situ temperature and under water flow (see above, section: Keeping of corals).

Two experiments were performed with non-processed natural seawater (NSW) to assess the potential role of corals for nutrient and organic matter dynamics and potential stimulation of the growth of prokaryotes and viruses in incubation water. One experiment was performed with bottom water collected from $590 \mathrm{~m}$ at the Clan mounds (NSW1), the other with bottom water from $777 \mathrm{~m}$ collected on the Haas mounds (NSW2). Three supplementary experiments were performed with (1) ultrafiltered (i.e. virus- and cell-free-) seawater (UF), (2) a combination of ultrafiltered and virus enriched seawater (VE) and (3) a combination of ultrafiltered and prokaryote enriched seawater (PE). For preparation of these seawater fractions see below (section: Ultrafiltration). These experiments also served to assess the potential role of corals for the dynamics of nutrient and TOC concentrations and potential stimulation of the growth of prokaryotes and viruses in incubation water at varying prokaryotic and viral abundances (long-term, T72h). However, additional questions were addressed using short-term dynamics (T11h) in these prokaryotic and viral manipulation experiments.

The five experiments were conducted one after the other using new coral micro-colonies and new incubation water (for each experiment). Incubation water was sampled for 3 days at T0h, T2h, T6h, T11h, T30h, T58h and T72h from all replicates.

\subsection{Surface area of corals}

The surface area of corals was measured from pictures of micro-colonies used in the experiments and placed on plotting paper with $\mathrm{mm}^{2}$ grids. The calculation was done using geometrical projections and area equations for geometric shapes and forms (Naumann et al., 2009) considering polyps and coenosteum as cylinders. The total surface area was then divided by the number of polyps, which averaged $373 \pm$ $48 \mathrm{~mm}^{2}$ for five colonies of $L$. pertusa and $126 \pm 13 \mathrm{~mm}^{2}$ for 5 colonies $M$. oculata. The surface area of the colonies used in the experiments was estimated by using the known amount of polyps.

\subsection{Ultrafiltration}

Tangential flow filtration was used to obtain different size fractions of seawater (for details see Weinbauer et al., 2009). Water samples (2001) were filtered through a $20 \mu \mathrm{m}$ net (Nitex) and $0.8 \mu \mathrm{m}$ filters (polycarbonate, $143 \mathrm{~mm}$ diameter); prokaryotes in the filtrate were concentrated using a Pellicon (Millipore) tangential flow filtration system. This system was equipped with an $0.2 \mu \mathrm{m}$ filter cartridge (Pellicon, Millipore) that was cleaned before with $0.1 \mathrm{~N} \mathrm{HCL}$ and flushed with 51 of MilliQ water and 101 of sample water before starting con- centration. The filtrate containing the majority of the viruses was processed using a $100 \mathrm{kDa}$ polyethersulfone tangential flow cartridge (Prep-Scale ${ }^{\mathrm{TM}} / \mathrm{TFF}, 0.54 \mathrm{~m}^{2}$ nominal filter area, Millipore; operated by a peristaltic pump at 1.5 bar) to obtain the viral concentrate and virus-(and cell-)free UF. This cartridge was cleaned with $0.1 \mathrm{~N} \mathrm{NaOH}$ and rinsed with 51 of MilliQ water and ca. 51 of $0.2 \mu \mathrm{m}$ filtrate prior to the concentration step. The concentration factor for prokaryotic and viral concentrates was ca. 500-1000. Following seawater fractions were made the day a supplementary experiment was set up: in the first experiment (experiment UF), only UF was used, in the second UF was combined with VE (experiment VE) and in the third UF was combined with PE (experiment $\mathrm{PE}$ ). All filtrations were carried out at in situ temperature $\left(9^{\circ} \mathrm{C}\right)$ in a temperature-controlled container. The time between water collection and start of the UF, VE and PE experiments was less than $3 \mathrm{~h}$.

\subsection{Analysis of inorganic nutrients and organic matter}

Five $\mathrm{ml}$ samples for quantifying nitrogen and phosphorus concentrations were collected in situ and from incubation water, filtered through a $0.2 \mu \mathrm{m}$ pore-size Acrodisc filter and measured directly onboard. Ammonium, nitrite, nitrate and dissolved inorganic phosphorus (DIP) concentrations were determined using an AxFlow Bran \& Luebbe Traacs800 autoanalyzer. The variability of the method is $<4 \%$ for all nutrients (Herfort et al., 2007). Dissolved inorganic nitrogen (DIN) concentrations were calculated as the sum of all nitrogen species.

For total organic carbon (TOC) analysis, $20 \mathrm{ml}$ samples were filled in precombusted glass ampoules, acidified with 8 drops of concentrated $\mathrm{H}_{2} \mathrm{SO}_{4}$, sealed and stored at $4{ }^{\circ} \mathrm{C}$ until analysis. TOC concentrations were measured by hightemperature combustion on a Shimadzu TOC-5000 as described in Benner and Strom (1993).

\subsection{Prokaryotic and viral abundance}

Samples for prokaryotic and viral abundance were fixed in glutaraldehyde ( $0.5 \%$ final concentration), kept at $4{ }^{\circ} \mathrm{C}$ in the dark for $15 \mathrm{~min}$, flash-frozen in liquid nitrogen and stored at $-80^{\circ} \mathrm{C}$ until analysis (within three months). This approach allows for sample preservation without losses of viruses (Brussaard, 2004). Bacterial and viral abundance were determined using SYBRGreen II (Invitrogen) and flow cytometry as described elsewhere (Brussaard, 2004; Brussaard et al., 2010; Gasol and del Giorgio, 2000).

\subsection{Calculations of turnover rates of micro-organisms}

The net change of prokaryotic and viral abundance in incubation water with corals is due to at least three mechanisms, i.e. direct release from corals, ingestion by corals and growth stimulation of prokaryotes and viruses by nutrient and mucus 
Table 1. In situ concentrations of nutrients and abundances of prokaryotes and viruses. Nutrients are given in $\mu \mathrm{M}$, prokaryotes as $10^{5}$ cells $\mathrm{ml}^{-1}$ and viruses as $10^{6}$ viruses $\mathrm{ml}^{-1}$. Exp, experiment; NSW, natural sea water; UF, ultrafiltrate; VE, virus-enriched; PE, prokaryote-enriched; DIN, dissolved inorganic nitrogen; DIP, dissolved inorganic phosphorus.

\begin{tabular}{ccccccccccc}
\hline Sample-ID & Depth $(\mathrm{m})$ & $\mathrm{NH}_{4}$ & $\mathrm{NO}_{3}$ & $\mathrm{NO}_{2}$ & $\mathrm{DIN}$ & $\mathrm{DIP}$ & $\mathrm{N}: \mathrm{P}$ & Prokaryotes & Viruses & Exp \\
\hline WK13 & 590 & 0.09 & 12.8 & 0.067 & 12.9 & 0.76 & 17.0 & 4.3 & 5.7 & NSW1 \\
WK42 & 583 & 0.20 & 11.3 & 0.109 & 11.6 & 0.74 & 15.6 & 4.3 & 8.4 & UF \\
WK79 & 745 & 0.23 & 11.6 & 0.085 & 11.9 & 0.75 & 16.0 & 4.4 & 7.5 & VE \\
WK86 & 770 & 0.16 & 11.7 & 0.093 & 11.9 & 0.73 & 16.3 & 4.9 & 6.9 & PE \\
WK110 & 777 & 0.18 & 13.1 & 0.081 & 14.1 & 0.83 & 16.1 & 4.0 & 7.0 & NSW2 \\
\hline
\end{tabular}

release. Thus, growth and production rates sensu strictu cannot be calculated for coral treatments. Instead, (net) changes of prokaryotes and viruses were calculated by using linear regressions of log transformed abundance data vs. time. Regressions were calculated from three to seven data points using the highest regression coefficients obtained ( $p$ always $<0.05$ ). For prokaryotes $r^{2}$ values ranged from $0.90-0.98$ with the exception of one value of 0.81 . For viruses, $r^{2}$ values ranged from 0.86 to 0.99 . Note that $\log$ transformed regression showed slightly higher regressions coefficients than non-transformed data. The slope of the regression was considered as turnover rate. For the controls, this is the equivalent to the (net) growth rate.

\subsection{Assessment of the influence of corals on nutrient, organic matter and microbial dynamics}

In order to assess the role of corals for the net change of nutrients, TOC, prokaryotes and viruses, following calculations were performed. In incubation water, the increases in inorganic nutrient concentrations in incubation water with corals were corrected for values in the controls. For nutrients, these increases were typically linear for 6-11 h; linear regression analyses were performed to obtain the net flux of nutrients in incubation water with corals. Coral-mediated nutrient flux was then calculated by multiplying these rates by the total volume of the incubation water and then normalizing the values to the surface area of the corals. In order to estimate organic carbon release from the corals, the increase of TOC measured after $6 \mathrm{~h}$ incubation in water with corals were corrected for the corresponding values in the controls. The organic matter release rate by corals was further calculated as described for nutrients. This method is similar to the beaker incubation technique, which is used to assess mucus release from corals (Herndl and Velimirov, 1986; Wild et al., 2008). The role of corals for the dynamics of prokaryotes and viruses was calculated from the turnover rates (corrected for data from the controls) as described for nutrients with net change rates being calculated by multiplying the turnover rate by the abundance at $\mathrm{TOh}$.

\subsection{Statistical analysis}

Mann-Whitney U-tests were used to assess for specific time points the difference of parameters between controls and coral treatments (separately for L. pertusa and M. oculata). Averages of the three different controls were used in this statistics, since ranges of the duplicates of the different types controls overlapped in all experiments. Wilcoxon signed rank tests were used to compare parameters across experiments between corals and the controls. Data for correlation analyses were $\log$ transformed to meet the requirements of normal distribution. A probability $(p)$ of $<0.05$ was considered significant for all statistical analyses.

\section{Results}

\subsection{In situ data}

The water collected at the study sites was similar in nutrient concentrations and prokaryotic and viral abundances (Table 1). The N:P ratio averaged $16.1 \pm 0.7$, in situ abundance was $4.4 \pm 0.3 \times 10^{5} \mathrm{ml}^{-1}$ for prokaryotes and $7.1 \pm 1.0 \times$ $10^{6} \mathrm{ml}^{-1}$ for viruses. TOC concentrations are only available for two stations (150 $\mu \mathrm{M}$ at WK13 and $147 \mu \mathrm{M}$ at WK110).

\subsection{General experimental approach}

At T0h, nutrient concentrations in the control did not differ significantly from values in incubation water with corals (Mann Whitney, $p>0.05$ for all experiments and both coral species) and were similar compared to in situ conditions, except for nigher ammonium concentrations in experiment NSW2 (Tables 1 and 2). At T0h, prokaryotic and viral abundance did not differ significantly between controls and incubation water with corals (Mann-Whitney, $p>0.05$ for all experiments and both coral species).

In the UF experiment, prokaryotic and viral abundance was reduced to ca. $10 \%$ relative to ambient at the start of the experiment (Table 2). In the VE experiment, viral abundance was 2-fold higher and prokaryotic abundance was reduced to $13 \%$. The presence of prokaryotic abundance in 
Table 2. Nutrient concentrations and prokaryotic and viral abundance in incubation water at the start of the experiments. Nutrient and TOC parameters are given in $\mu \mathrm{M}$, prokaryotes as $10^{5}$ cells $\mathrm{ml}^{-1}$ and viruses as $10^{6}$ viruses $\mathrm{ml}^{-1}$. Data are given as averages $\pm \mathrm{SE}$ of 3 replicates. Exp, experiment; NSW, natural sea water; UF, ultrafiltrate; VE, virus-enriched; PE, prokaryote-enriched; DIN, dissolved inorganic nitrogen; DIP, dissolved inorganic phosphorus.

\begin{tabular}{cccccccccc}
\hline Exp & $\mathrm{NH}_{4}$ & $\mathrm{NO}_{3}$ & $\mathrm{NO}_{2}$ & DIN & DIP & $\mathrm{N}: \mathrm{P}$ & $\mathrm{TOC}$ & Prokaryotes & Viruses \\
\hline NSW1 & $0.30 \pm 0.09$ & $13.3 \pm 3.3$ & $0.07 \pm 0.02$ & $13.7 \pm 3.2$ & $0.86 \pm 0.26$ & $15.9 \pm 3.7$ & $140 \pm 3$ & $4.6 \pm 0.7$ & $4.6 \pm 0.3$ \\
NSW2 & $1.72 \pm 0.41$ & $13.9 \pm 4.2$ & $0.10 \pm 0.02$ & $15.7 \pm 4.1$ & $0.99 \pm 0.27$ & $15.9 \pm 4.2$ & $160 \pm 24$ & $3.4 \pm 0.4$ & $3.6 \pm 0.5$ \\
UF & $0.12 \pm 0.03$ & $12.5 \pm 2.9$ & $0.09 \pm 0.02$ & $12.7 \pm 2.9$ & $0.75 \pm 0.18$ & $16.9 \pm 3.9$ & $71 \pm 2$ & $0.56 \pm 0.01$ & $0.07 \pm 0.01$ \\
VE & $0.32 \pm 0.03$ & $11.6+0.1$ & $0.11 \pm 0.01$ & $12.0 \pm 0.1$ & $0.74 \pm 0.01$ & $16.3 \pm 0.1$ & $83 \pm 3$ & $0.64 \pm 0.07$ & $13.9 \pm 0.8$ \\
PE & $0.44 \pm 0.10$ & $11.6 \pm 2.7$ & $0.10 \pm 0.02$ & $12.1 \pm 2.8$ & $0.72 \pm 0.17$ & $16.9 \pm 3.9$ & $79 \pm 1$ & $10.3 \pm 0.1$ & $6.4 \pm 0.1$ \\
\hline
\end{tabular}

Table 3. Nutrient and total organic carbon (TOC) concentrations and microbial abundances at the end of the experiments. Nutrient and TOC parameters are given in $\mu \mathrm{M}$, prokaryotes as $10^{5}$ cells $\mathrm{ml}^{-1}$ and viruses as $10^{6}$ viruses $\mathrm{ml}^{-1}$. Data are given as averages $\pm \mathrm{SE}$ of 3 replicates NSW, natural sea water; UF, ultrafiltrate; VE, virus enriched; PE, prokaryote enriched; C, control, Lp; L. pertusa; Mo, M. oculata; VE, virus enhanced; PE, prokaryote enhanced; DIN, dissolved inorganic nitrogen; DIP, dissolved inorganic phosphorus, NS, not significant (Wilcoxon, $p \geq 0.05$ ); * significant difference (Mann-Whitney, $p<0.05$ ) between coral and control treatment.

\begin{tabular}{|c|c|c|c|c|c|c|c|c|c|c|}
\hline Exp. & Treatm. & $\mathrm{NH}_{4}$ & $\mathrm{NO}_{3}$ & $\mathrm{NO}_{2}$ & DIN & DIP & $\mathrm{N}: \mathrm{P}$ & TOC & Prokaryotes & Viruses \\
\hline \multirow[t]{3}{*}{ NSW1 } & $\mathrm{C}$ & $0.5 \pm 0.1$ & $13.4 \pm 0.1$ & $0.33 \pm 0.04$ & $14.2 \pm 0.1$ & $0.67 \pm 0.02$ & $21 \pm 1$ & $157 \pm 25$ & $0.8 \pm 0.2$ & $1.3 \pm 0.1$ \\
\hline & Lp & $14.5 \pm 3.1^{*}$ & $13.7 \pm 0.1^{*}$ & $0.34 \pm 0.04$ & $28.5 \pm 0.1^{*}$ & $0.24 \pm 0.11^{*}$ & $119 \pm 13 *$ & $220 \pm 23 *$ & $2.9 \pm 0.3^{*}$ & $0.9 \pm 0.1 *$ \\
\hline & Mo & $3.9 \pm 1.8^{*}$ & $13.0 \pm 0.2$ & $0.44 \pm 0.03^{*}$ & $17.9 \pm 0.9^{*}$ & $0.13 \pm 0.01^{*}$ & $133 \pm 4 *$ & $267 \pm 67^{*}$ & $4.9 \pm 0.9^{*}$ & $0.6 \pm 0.1^{*}$ \\
\hline \multirow{2}{*}{ NSW2 } & $\mathrm{Lp}$ & $23.0 \pm 6.8^{*}$ & $13.9 \pm 0.1$ & $0.36 \pm 0.06^{*}$ & $37.3 \pm 0.1^{*}$ & $1.62 \pm 0.06^{*}$ & $23 \pm 1^{*}$ & $256 \pm 71 *$ & $5.1 \pm 1.2 *$ & $4.1 \pm 0.6^{*}$ \\
\hline & Mo & $25.1 \pm 2.0^{*}$ & $14.0 \pm 0.1$ & $0.24 \pm 0.03^{*}$ & $39.3 \pm 0.1^{*}$ & $1.72 \pm 0.08^{*}$ & $23 \pm 1^{*}$ & $187 \pm 12^{*}$ & $7.1 \pm 0.4 *$ & $2.2 \pm 0.2 *$ \\
\hline UF & $\mathrm{C}$ & $0.2 \pm 0.1$ & $10.2 \pm 0.3$ & $0.21 \pm 0.01$ & $10.7 \pm 0.3$ & $0.43 \pm 0.05$ & $25 \pm 4$ & $103 \pm 21$ & $1.0 \pm 0.1$ & $0.5 \pm 0.2$ \\
\hline \multirow[t]{3}{*}{ VE } & $\mathrm{C}$ & $0.2 \pm 0.1$ & $9.9 \pm 0.3$ & $0.15 \pm 0.01$ & $10.2 \pm 0.3$ & $0.56 \pm 0.05$ & $18 \pm 1$ & $79 \pm 11$ & $1.1 \pm 0.2$ & $1.3 \pm 0.1$ \\
\hline & $\mathrm{Lp}$ & $13.6 \pm 0.9^{*}$ & $11.7 \pm 0.1^{*}$ & $0.17 \pm 0.01$ & $25.5 \pm 0.1^{*}$ & $0.71 \pm 0.08^{*}$ & $36 \pm 2 *$ & $158 \pm 21 *$ & $2.2 \pm 0.1 *$ & $2.0 \pm 0.2^{*}$ \\
\hline & Mo & $2.3 \pm 0.5^{*}$ & $11.4 \pm 0.1^{*}$ & $0.16 \pm 0.01$ & $13.9 \pm 0.1^{*}$ & $0.36 \pm 0.03$ & $39 \pm 2 *$ & $143 \pm 29 *$ & $2.1 \pm 0.2 *$ & $2.1 \pm 0.1^{*}$ \\
\hline \multirow[t]{3}{*}{ PE } & $\mathrm{C}$ & $0.2 \pm 0.1$ & $9.6 \pm 0.4$ & $0.18 \pm 0.03$ & $10.0 \pm 0.2$ & $0.52 \pm 0.02$ & $22 \pm 1$ & $82 \pm 14$ & $2.0 \pm 0.1$ & $0.8 \pm 0.1$ \\
\hline & $\mathrm{Lp}$ & $36.6 \pm 3.4^{*}$ & $11.7 \pm 0.1^{*}$ & $0.59 \pm 0.07 *$ & $48.9 \pm 0.1^{*}$ & $1.66 \pm 0.08^{*}$ & $30 \pm 1 *$ & $164 \pm 28^{*}$ & $5.2 \pm 1.7^{*}$ & $3.4 \pm 0.2^{*}$ \\
\hline & Mo & $14.3 \pm 1.1^{*}$ & $11.7 \pm 0.1^{*}$ & $0.28 \pm 0.09 *$ & $26.3 \pm 0.1 *$ & $1.08 \pm 0.23^{*}$ & $24 \pm 1^{*}$ & $117 \pm 3^{*}$ & $3.2 \pm 0.4^{*}$ & $1.7 \pm 0.3^{*}$ \\
\hline
\end{tabular}

UF and VE is due to regrowth during preparation of seawater fractions. In the PE experiment, prokaryotic abundance was elevated by 2.6 fold and viral abundance reduced to $9 \%$. The viruses in the PE experiment were introduced into the incubations along with the prokaryotic concentrate, since not all viruses pass a $0.2 \mu \mathrm{m}$ filter. Overall, the experiments resulted in a range of viral and prokaryotic abundances both higher and lower than in situ and thus, experimental intentions were met.

\subsection{Dynamics of nutrients and organic carbon in incubations}

Data on the dynamics of nutrient concentrations in the experiments are summarized in Tables 2 and 3; an example is shown in Fig. 2. Experiments differed in the detailed dynamics and concentrations of nutrients. However, there were also common trends. This is shown in the following mainly for T72h (Table 3), except when short-term incubations showed a different trend. In all experiments, ammonium, nitrate, nitrite and DIN concentrations increased with time (at least during an initial phase). The concentrations of ammonium and DIN were significantly higher in the incubations with corals than in the controls (Mann-Whitney, $p<0.05$ for all experiments and both coral species; Wilcoxon, $p<0.05$ across experiments for both species). Nitrate concentrations were higher in the coral treatments than in the controls in the UF, VE and PE experiments (Mann-Whitney, $p<0.05$ ). In the NSW experiments, nitrate concentrations were only 

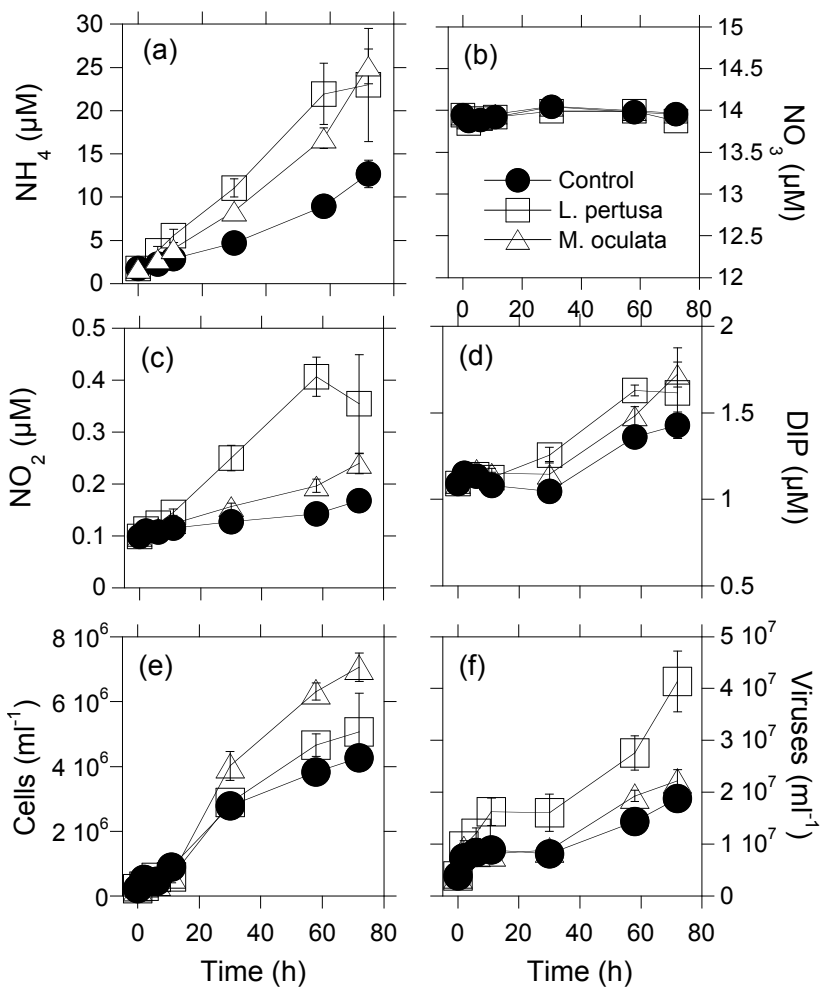

Fig. 2. Dynamics of ammonium, nitrate, nitrite and DIP concentrations, and prokaryotic and viral abundance in experiment NSW2. Note that DIN shows the same trend as ammonium. Data are given as averages \pm SE of 3 replicates. When error bars are not visible, they are within the width of the symbol.

significantly higher in the coral treatment than in the controls for L. pertusa in NSW1 (Mann-Whitney, $p<0.05$ ). Nitrite concentrations were higher in coral treatments than in controls, however, this trend was only significant in some experiments (Mann-Whitney, $p<0.05$ for L. pertusa in NSW1 and VE and for M. oculata in UF and VE). Nevertheless, this trend was significant across experiments for both species (Wilcoxon, $p<0.05$ ). The dynamics of DIP differed between experiments. DIP concentrations were in three experiments significantly higher in incubation water with corals than in controls (NSW2, UF, PE) and in one experiment significantly lower (NSW1) (Mann-Whitney, $p<0.05$ ). However, when data from short-term incubations $(6-11 \mathrm{~h})$ are used, DIP concentrations were significantly higher in the corals treatments than in controls (Wilcoxon, $p<0.05$ across experiments for both species; data not shown). In all experiments $\mathrm{N}: \mathrm{P}$ ratios were significantly higher in incubation water with corals than in the controls (Mann-Whitney, $p<0.05$ for all experiments and both species; Wilcoxon, $p<0.05$ for both species).

TOC concentrations at T0h were $160 \mu \mathrm{M}$ in NSW1 and $140 \mu \mathrm{M}$ in NSW2 and ranged from $71-83 \mu \mathrm{M}$ in the other experiments (Table 2). In all experiments, TOC concentrations in the controls were similar at $\mathrm{T} 72 \mathrm{~h}$ compared to T0h (Table 3). However, at T72h, TOC concentrations were significantly higher in incubation water with corals than in the controls (Mann-Whitney, $p<0.05$ for all experiments and both species expect $M$. oculata in the UF experiment; Wilcoxon, $p<0.05$ for both species).

\subsection{Dynamics of prokaryotes and viruses in incubations}

Prokaryotic abundance increased with time in all treatments. At the end of the incubations, prokaryotic abundances were significantly higher in incubation water with corals than in controls (Mann-Whitney, $p<0.05$ for all experiments and both species; Wilcoxon, $p<0.05$ across experiments for both species; Table 3). Across experiments, prokaryotic turnover rate averaged $0.6 \pm 0.2 \mathrm{~d}^{-1}$ in the controls, $1.2 \pm 0.2 \mathrm{~d}^{-1}$ for L. pertusa and $1.3 \pm 0.3 \mathrm{~d}^{-1}$ for M. oculata (Fig. 3a); turnover rates were significantly higher in incubation water with corals than in the controls (Mann-Whitney, $p<0.05$ for all experiments and both species; Wilcoxon, $p<0.05$ across experiments for both species).

With the exception of NSW1, viral abundance was significantly higher in incubation water with corals than in the controls (Mann-Whitney, $p<0.05$ ) (Table 3). Across experiments, viral turnover rates averaged $0.25 \pm 0.06 \mathrm{~d}^{-1}$ in the controls, $0.43 \pm 0.06 \mathrm{~d}^{-1}$ in incubation water with $L$. pertusa and $0.43 \pm 0.12 \mathrm{~d}^{-1}$ in incubation water with $M$. oculata. In all experiments, viral turnover rates were higher in incubation water with corals than in incubation water of the controls (Fig. 3b), however, this difference was not significant in the UF experiment (Mann-Whitney, $p>0.05$ ). Nevertheless, across experiments, viral turnover rates were significantly higher in coral treatments than in the controls (Wilcoxon, $p<0.05$ for both species).

\subsection{Organic carbon release and stimulation of nutri- ents, prokaryotes and viruses by corals}

The two experiments, where the abundance of prokaryotes and viruses was not manipulated (NSW) were used to assess organic carbon release and the potential for stimulation of the nutrient flux and prokaryotic and viral abundances by corals (Table 4). The estimated organic carbon release rate averaged $23 \pm 6 \mathrm{mg} \mathrm{C} \mathrm{m}^{-2} \mathrm{~h}^{-1}$ for L. pertusa and $21 \pm 8 \mathrm{mg}$ $\mathrm{C} \mathrm{m}^{-2} \mathrm{~h}^{-1}$ for M. oculata (Table 4). The DIN flux was on average $0.99 \pm 0.09 \mathrm{mg} \mathrm{N} \mathrm{m}^{-2} \mathrm{~h}^{-1}$ for $L$. pertusa and $0.49 \pm 0.15 \mathrm{mg} \mathrm{N} \mathrm{m}^{-2} \mathrm{~h}^{-1}$ for M. oculata. For DIP, the average flux was $0.037 \pm 0.001 \mathrm{mg} \mathrm{P} \mathrm{m}^{-2} \mathrm{~h}^{-1}$ for $L$. pertusa and $0.023 \pm 0.001 \mathrm{mg} \mathrm{P} \mathrm{m}^{-2} \mathrm{~h}^{-1}$ for M. oculata. The prokaryotic stimulation averaged $6.0 \pm 3.0 \times 10^{9}$ cells m$^{-2} \mathrm{~h}^{-1}$ for $L$. pertusa and $8.4 \pm 2.9 \times 10^{9}$ cells $\mathrm{m}^{-2} \mathrm{~h}^{-1}$ for M. oculata. Viral stimulation averaged $15.6 \pm 12.7 \times 10^{9}$ particles $\mathrm{m}^{-2} \mathrm{~h}^{-1}$ for L. pertusa and $4.3 \pm 0.4 \times 10^{9}$ particles $\mathrm{m}^{-2} \mathrm{~h}^{-1}$ for $M$. oculata. Across experiments, coral-mediated ammonium and 
Table 4. Organic carbon release and stimulation of nutrients, prokaryotes and viruses in incubation water with corals (corrected for controls). For calculations see "Material and methods". Nutrient parameters and TOC are given in $\mathrm{mg} \mathrm{m}^{-2}$ coral surface $\mathrm{h}^{-1}$, prokaryotes as $10^{9}$ cells and viruses as $10^{9}$ viruses $\mathrm{m}^{-2}$ coral surface $\mathrm{h}^{-1}$. Data are given as averages \pm SE of 3 replicates. NSW, natural seawater; UF, ultrafiltrate; VE, virus-enriched; PE, prokaryote-enriched; DIN, dissolved inorganic nitrogen; DIP, dissolved inorganic phosphorus; ND, not detectable (i.e. statistically not different from or lower than controls).

\begin{tabular}{|c|c|c|c|c|c|c|c|c|c|}
\hline Exp. & Species & $\mathrm{NH}_{4}$ & $\mathrm{NO}_{3}$ & $\mathrm{NO}_{2}$ & DIN & DIP & TOC & Prokaryotes & Viruses \\
\hline \multirow[t]{2}{*}{ NSW1 } & $\mathrm{Lp}$ & $0.97 \pm 0.21$ & $0.055 \pm 0.001$ & ND & $1.08 \pm 0.01$ & $0.040 \pm 0.018$ & $28.5 \pm 3.0$ & $3.0 \pm 0.3$ & $28.2 \pm 3.1$ \\
\hline & Mo & $0.48 \pm 0.22$ & $0.129 \pm 0.002$ & $0.0180 \pm 0.0007$ & $0.63 \pm 0.03$ & $0.023 \pm 0.001$ & $29.0 \pm 7.3$ & $5.5 \pm 1.0$ & $4.7 \pm 0.8$ \\
\hline NSW2 & Mo & $0.34 \pm 0.03$ & ND & $0.0032 \pm 0.0004$ & $0.34 \pm 0.01$ & $0.022 \pm 0.001$ & $12.3 \pm 0.8$ & $11.3 \pm 0.6$ & $3.9 \pm 0.3$ \\
\hline \multirow{2}{*}{ UF } & Lp & $1.53 \pm 0.23$ & $0.118 \pm 0.001$ & $0.0019 \pm 0.0002$ & $1.65 \pm 0.01$ & $0.023 \pm 0.005$ & $12.9 \pm 2.0$ & $10.4 \pm 0.3$ & $9.4 \pm 2.7$ \\
\hline & Mo & $0.43 \pm 0.01$ & $0.014 \pm 0.001$ & $0.0020 \pm 0.0001$ & $0.45 \pm 0.01$ & $0.011 \pm 0.009$ & $7.3 \pm 2.1$ & $4.8 \pm 0.3$ & $7.3 \pm 0.6$ \\
\hline \multirow[t]{2}{*}{ PE } & Lp & $1.54 \pm 0.20$ & $0.039 \pm 0.001$ & $0.0120 \pm 0.0014$ & $1.59 \pm 0.01$ & $0.030 \pm 0.002$ & $14.5 \pm 2.5$ & $8.4 \pm 2.8$ & $7.1 \pm 0.4$ \\
\hline & Mo & $0.52 \pm 0.04$ & $0.014 \pm 0.001$ & $0.0035 \pm 0.0011$ & $0.54 \pm 0.01$ & $0.025 \pm 0.005$ & $8.4 \pm 0.2$ & $1.9 \pm 0.2$ & $1.5 \pm 0.3$ \\
\hline
\end{tabular}

\section{Wilcoxon test}

Lp vs. Mo $(p)$

$<0.05$

NS

NS

$<0.05$

NS

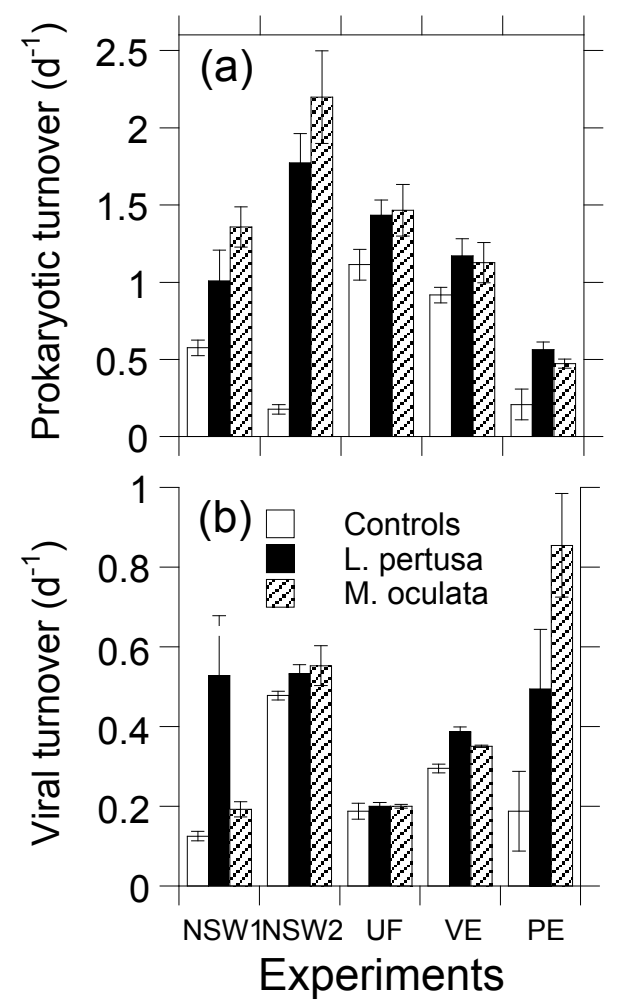

DIN flux was higher for $L$. pertusa than for M. oculata (Wilcoxon, $p<0.05$ ).

Nutrient, prokaryotic and viral stimulation by corals showed no consistent differences between experiments using NSW as incubation water and experiments with incubation water, where the abundances of viruses and prokaryotes was manipulated (Table 4). In contrast organic carbon release was slightly higher in the NSW than in the other experiments.

\subsection{Short-term dynamics in prokaryotic and viral ma- nipulation experiments}

The short-term dynamics (up to $11 \mathrm{~h}$ ) of prokaryotic and viral abundance was monitored in the experiments, in which microbial abundances were manipulated. In the UF experiment, prokaryotic abundance remained constant in the controls during the first $2 \mathrm{~h}$, whereas in incubation water with corals, prokaryotic abundance increased by 50-80\% (Fig. 4a). This difference was significant (Mann Whitney, $p<0.05$ for both species). Viral abundance decreased slightly in the controls and was at T2h 2.2-fold higher in incubation water with L. pertusa and 3.2-fold higher in M. oculata (Fig. 4b) and this difference was significant for both coral species (MannWhitney, $p<0.05)$. After $6 \mathrm{~h}$, the differences between controls and incubation water with $M$. oculata were even more pronounced.

In the VE experiment, prokaryotic abundance was slightly higher at T6h in incubation water with corals than in controls, however, this difference was only significant for incubation water with M. oculata (Mann-Whitney, $p<0.05$; Fig. 4c). Viral abundance decreased during $\mathrm{T} 0-11 \mathrm{~h}$ in all treatments and the decay was lowest in the coral treatments (Fig. 4d).

Fig. 3. Prokaryotic and viral turnover rates in the experiments. Data are given as averages \pm SE of 3 replicates.

In the PE experiment, prokaryotic abundance was for no time-point significantly different between incubation water with corals and the controls (Mann-Whitney, $p>0.05$; Fig. 4e). From T0h to T6h, viral abundance in incubation 

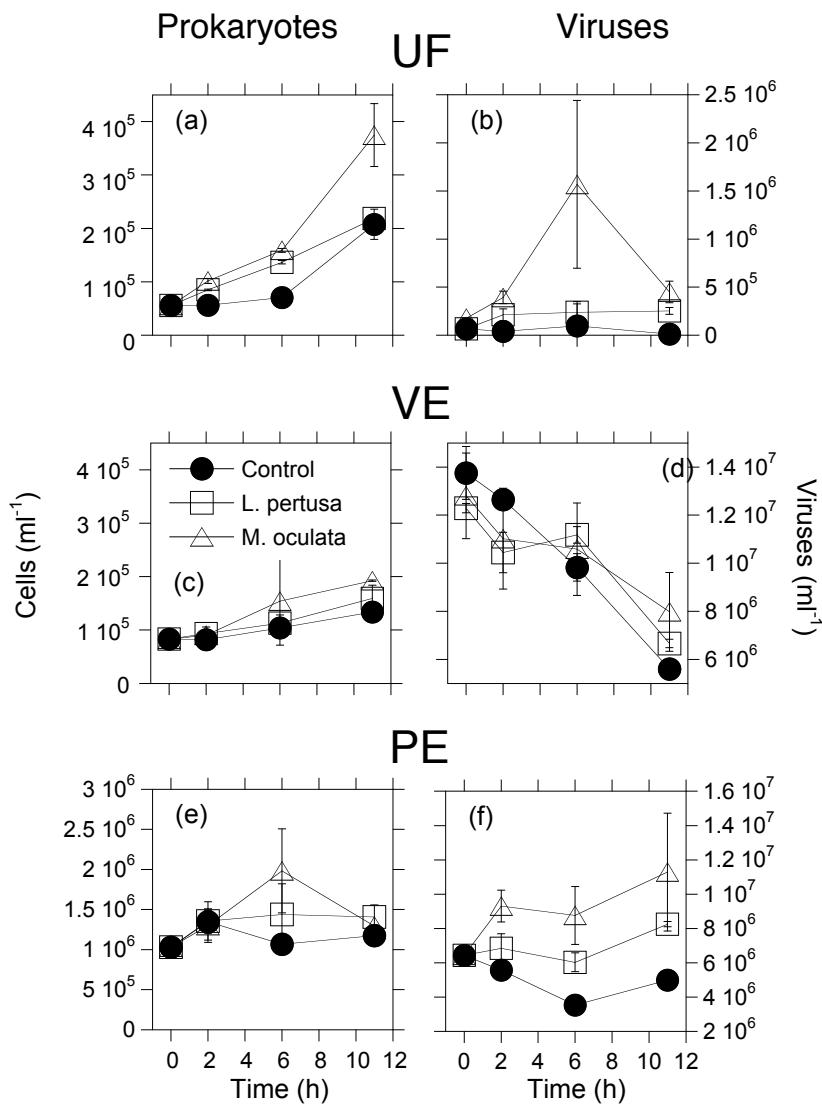

Fig. 4. Short-term dynamics of prokaryotic and viral abundance in the experiments, where prokaryotic and viral abundance was manipulated. Note that axis can be different between experiments. Data are given as averages \pm SE of 3 replicates. When error bars are not visible, they are within the width of the symbol. The decrease of viral abundance in the VE treatment is likely due to the strong enhancement of viral abundance and the low prokaryotic abundance thus, resulting in viral production that is much lower than viral decay. UF, ultrafiltrate; VE, virus-enriched; PE, prokaryote-enriched.

water of the controls of experiment PE decreased, whereas viral abundance increased or remained constant in incubation water with corals; between $\mathrm{T} 2 \mathrm{~h}$ and $\mathrm{T} 11 \mathrm{~h}$, values were for all time points significantly higher for L. pertusa and M. oculata than in the controls (Mann-Whitney, $p<0.05$; Fig. 4f).

\subsection{Correlation analysis}

Correlations were performed from means from all data points per experiments except T0h. In all experiments (except NSW1), viral abundance increased significantly with prokaryotic abundance $\left(R^{2}=0.50-0.78, p<0.001, n=18\right)$.

\section{Discussion}

This study integrates data on the dynamics of nutrients, organic carbon, prokaryotes and viruses in onboard incubations with the cold-water corals $L$. pertusa and $M$. oculata. To overcome or at least reduce the potential problem of large variation between specimens (van Duyl et al., 2008; Maier et al., 2009), three coral colonies per replicate incubation and several types of controls were used. However, the five experiments could not be performed in parallel thus, variability was introduced in this way. Also, stress such as caused by handling or by changes in hydrostatic pressure could have introduced variability. Moreover, the reported rates should be viewed with caution, although data from short-term incubations were typically used to reduced incubation artifacts. Nevertheless, common trends could be found in incubations with both coral species across 5 experiments. The most consistent trends were a release of DIN, DIP and mucus, an increase of the N:P ratios, potential detachment of prokaryotes and viruses and a stimulation of prokaryotic and viral growth. Also, the finding that the parameters did not differ between the various types of controls (seawater with and without corals skeletons) suggests that the living coral was responsible for the observed trends in the presence of corals (and not e.g. the presence of a skeleton surface).

\subsection{Prokaryotic and viral abundance in bottom water}

Prokaryotic and viral abundance in situ averaged $4.4 \times$ $10^{5}$ cells $\mathrm{ml}^{-1}$ and $7.1 \times 10^{6}$ viruses $\mathrm{ml}^{-1}$, respectively. Thus, the prokaryotic abundances determined by flow cytometry were similar to the average of $4.9 \times 10^{5} \mathrm{ml}^{-1}$ from other stations of the same study site enumerated by epifluorescence microscopy (van Duyl et al., 2008). To the best of our knowledge there are no other data on prokaryotic and viral abundances from other CWC reefs. In mesopelagic waters of the North Atlantic, abundances were lower than at the CWC reefs at Rockall Bank (583-777 m) with average values of $1.5 \times 10^{5}$ cells ml$^{-1}$ and $1.8 \times 10^{6}$ viruses $\mathrm{ml}^{-1}$ between $250-500 \mathrm{~m}$ and $0.5 \times 10^{5}$ cells ml ${ }^{-1}$ and $1.3-1.8 \times 10^{6}$ viruses $\mathrm{ml}^{-1}$ between $900-1100 \mathrm{~m}$ (Parada et al., 2007). The data suggest that CWC bottom water is enriched with respect to prokaryotic and viral abundance.

\subsection{Nutrient dynamics and mucus release}

The concentrations of ammonium, nitrite, DIN and DIP were typically higher in incubation water with corals than in controls and the strongest effect was found for ammonium. An enrichment with respect to nitrite, nitrate and DIN has been found in the interstitial water of tropical and temperate corals (Schiller and Herndl, 1989) and in coral reef cavities (Van Duyl et al., 2006; Scheffers et al., 2005). There was no consistent difference in the rates of nutrient flux (ammonium, nitrite, DIN and DIP) between experiments with NSW as incubation water and experiments with incubation water, where viral and prokaryotic abundance was manipulated (Table 4). In two of these experiments (UF and VE) prokaryotic abundances were strongly reduced and thus, have probably not 
strongly influenced the nutrient dynamics (as estimated in short-term incubations). Thus, the prokaryotic consumption and transformation of nutrients was likely less important than release from corals. As a consequence, the coral-mediated nutrient fluxes given in Table 4 can serve as a first estimation of coral-mediated nutrient release. Overall, the cold-water corals seem to release DIN and DIP into the ambient water. The dominance of ammonium in the experiments with corals compared to the relatively low concentrations in situ suggests rapid dilution of ammonium or rapid nitrification in situ.

Release of mucus has been documented before for temperate (e.g. Herndl and Velimirov, 1986; Schiller and Herndl, 1989), tropical (e.g. Ducklow and Mitchell, 1979b; Wild et al., 2004) and cold-water corals (Wild et al., 2008). Mucus release was $17-29 \mathrm{mg} \mathrm{C} \mathrm{m}^{-2} \mathrm{~h}^{-1}$ for L. pertusa. This is lower than the mucus release of ca. $48 \mathrm{mg} \mathrm{C} \mathrm{m}^{-2} \mathrm{~h}^{-1}$ found for the same species collected in a Norwegian Fjord by using a similar approach (Wild et al., 2008). This difference could be due to the different techniques used for assessing coral surface area (geometry vs computer tomography). However, geometry and computer tomography yield similar results including L. pertusa (Naumann et al., 2009). Using a correction for relating surface areas of $L$. pertusa as determined by geometry to computer tomography estimates (Naumann et al., 2009) mucus release would be up to $36 \mathrm{mg} \mathrm{C} \mathrm{m}^{-2} \mathrm{~h}^{-1}$ in our study and thus, even closer to published values (Wild et al., 2008). The data from our study were from corals collected in 583-777 m depth from the Rockall Bank CWC reefs and incubated onboard, whereas the data from Wild et al. (2008) were from a colony collected in $120 \mathrm{~m}$ depth in a fjord off Bergen and kept in an aquarium for six months before the mucus release assay was performed. Considering these differences, the mucus release rates are surprisingly similar in the two studies. Also, first estimates of mucus release are provided for $M$. oculata and show that release rates were similar (12-29 $\mathrm{mg} \mathrm{C} \mathrm{m}^{-2} \mathrm{~h}^{-1}$ ) compared to L. pertusa. Overall, the data support the finding that cold-water corals belong to the species with relatively low mucus production rates (Wild et al., 2008).

\subsection{Release of prokaryotes and viruses from corals}

The UF experiment was designed to reduce background levels of prokaryotes and viruses to be able to detect the potential release of prokaryotes and viruses from corals. Data from the UF (and VE) experiments indicate that prokaryotic abundances were already elevated at $\mathrm{T} 2 \mathrm{~h}$ in the coral treatments (Fig. 4). The observed increase would correspond to doubling times of as low as $1.1 \mathrm{~h}$ in incubation water with corals. However, such doubling times are unrealistic. Prokaryotic turnover times in bottom water from the CWC reef of Rockall Bank as determined by incorporation of radioactively labelled substrates ranged from 2.5-5 days (van Duyl et al., 2008) and in the onboard experiments, they ranged from ca. $0.5-5$ days (Fig. $3 a$ ). Thus, it is more likely that prokaryotes became detached from corals or were released along with mucus.

Data from the UF and PE experiments indicate that viral abundances at T2-6h were higher in the coral treatments than in the controls. It is known that stimulated host growth can increase phage production, e.g. by an increased burst size (i.e. the number of viruses released during the lysis of a cell) (Parada et al., 2006). Consequently, nutrient and mucus release from the corals (see below, section: Nutrient dynamics and mucus release) could have enhanced the growth of hosts and caused an increase in burst size or phage assembly rate in cells. In situ evidence from diurnal studies suggests that such an increase in burst size is at maximum 2-fold (Parada et al., 2006). Since viral abundance was stimulated at $\mathrm{T} 2 \mathrm{~h}-$ T6h by up to 3.6-fold in incubation water with $L$. pertusa and by up to 24 -fold in incubation water with $M$. oculata, it is unlikely that a stimulated phage production was the only source for the elevated viral abundance in incubation water with corals. It is also conceivable that viruses were released from corals, e.g. by detachment from mucus or along with mucus release. It has been shown that viruses are present in coral mucus (Davy and Patten, 2007) including L. pertusa (Weinbauer, unpublished data) and that the virus-to-bacteria ratio was higher over living than over dead corals (Patten et al., 2006). Moreover, electron microscopy pictures indicate release of viruses from heat-stressed corals (Davy et al., 2006). Currently, it is not known whether the released viruses are only from prokaryotes or also from the coral animals.

\subsection{Mechanisms stimulating viral and microbial pro- duction in incubations with corals}

Our data suggest that cold-water corals can be a source of prokaryotes and viruses for the free-living community. However, the stimulation of prokaryotes in incubations with corals was also influenced by other factors such as mucus release. This is supported by the finding that the respiration of microbial plankton was enhanced in incubations with mucus of L. pertusa (Wild et al., 2009). Also, stimulation of prokaryotic growth by mucus has been demonstrated before for temperate (Schiller and Herndl, 1989) and tropical corals (Ferrier-Pagès et al., 2000). Inorganic nutrient release as a result of digestion processes by the corals could have ensured that the utilization of carbon rich mucus was not limited by inorganic nutrients. Indeed, at the end of the experiments nutrient concentrations were $>9 \mu \mathrm{M}$ nitrate and $>0.1 \mu \mathrm{M}$ DIP thus, suggesting no limitation by inorganic $\mathrm{N}$ or P. As the concentration of inorganic nutrients is high in situ and thus, potentially not growth limiting in bottom waters of CWC reefs (Table 1), our experimental approach was likely - in this respect - mimicking general CWC bottom water conditions, where mucus release concurs with nutrient replenishment.

Virus were typically also stimulated in incubation water with the corals L. pertusa and M. oculata. Such experimental 
data are not available for temperate or tropical corals, although an in situ study suggests that viruses are stimulated close to coral surfaces (Patten et al., 2006), a finding which concurs with our experimental data. The finding that prokaryotic and viral abundance were typically well correlated in the experiments indicates that the stimulation of prokaryotic production also stimulated viral production. As viral infection is a stochastic event (Murray and Jackson, 1992), this is possibly a consequence of increased encounter rates of viruses with host cells.

\subsection{Implications}

The finding of enhanced nutrient turnover, mucus release and growth stimulation of prokaryotes and viruses by corals has several implications. The data suggest that $\mathrm{CWC}$ reefs are a source of DIN and increase N:P ratios in surrounding waters. Interestingly, these reefs often occur in depths, where inorganic nitrogen species are converted to molecular nitrogen by denitrification and anammox processes (300-700 m) (Capone and Knapp, 2007; Deutsch et al., 2007) thus, resulting in a N:P ratio lower than the Redfield ratio. Since CWC reefs on continental margins are more frequent than previously thought (Roberts et al., 2006), they might replenish nitrogen species and influence the nitrogen cycle in these areas and counterbalance the low N:P ratios in the sediment.

Work by Wild and co-workers (Wild et al., 2009, 2008) has suggested that CWC reefs could stimulate microbial activity in bottom water by mucus release and potentially exert some control over organic $\mathrm{C}$ cycling. Our data confirm mucus release and suggest a stimulation for prokaryotic growth and thus, support the idea that CWC reefs sustain microbial activity. This could explain why prokaryotic (and viral) abundances seem to be stimulated in bottom water of CWC reefs (see above, section: Prokaryotic and viral abundance in bottom water). Viruses exert a major influence on the regeneration of organic matter in marine pelagic environments (Middelboe and Lyck, 2002; Motegi et al., 2009; Suttle, 2005). As this influence depends on the rate of viral lysis (Motegi et al., 2009), a stimulation of viral production by corals in bottom water could enhance the remineralization of organic matter and lubricate the microbial food web in bottom water of CWC reefs.

An elevated prokaryotic production could also stimulate the nutrition of corals, since ingestion of prokaryotic cells is a density dependant process (Houlebrèque et al., 2004). Ingestion of viruses has been documented so far for sponges (Hadas et al., 2006) but not for corals. As (most) viruses are per definition part of the DOC pool which is accessible to corals (Sorokin, 1973), one might also expect uptake of viruses. A feed-back loop can be envisioned, where enhanced prokaryotic (and viral) production has a positive upward cascading effect through the trophic levels of the food web and finally fuels zooplankton (Peduzzi and Herndl, 1992). This enhanced zooplankton production (and other stimulated trophic levels) could then be cropped by corals thus, closing the trophic loop. This could also explain the apparent contradiction of DIN release (this study) and the finding that $\mathrm{CWC}$ reefs preferentially remove nitrogen (Lavaleye et al., 2009). Such a recycling mechanism could result in a reduced loss of elements such as $\mathrm{N}, \mathrm{P}$ and $\mathrm{C}$ from CWC reefs. Overall, the study suggests that corals are a strong forcing factor for the microbial food web of the bottom water in CWC reefs via the release of nutrients and mucus.

Acknowledgements. We thank the captain and the crew of the RV Pelagia for their support. We also thank the supporting departments at NIOZ for co-ordination, data management, technical and analytical support. The comments of two anonymous reviewers strongly improved the manuscript. This research was financed by the Dutch NWO/ALW project BIOSYS (no. 835.30.024 and 814.01.005). Additional support came from a Marie-Curie Fellowship (MECCA) to CM, the Prince Albert II Foundation (Project No: 284), the ANR-AQUAPHAGE (No. ANR 07 BDIV 015-06) and ANR-MAORY (No. ANR 07 BLAN 016) and the European Project on Ocean Acidification (EPOCA, FP7/2007-2013 under grant agreement no. 211384).

Edited by: G. Herndl

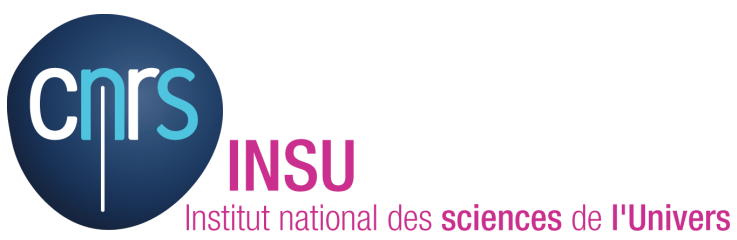

The publication of this article is financed by CNRS-INSU.

\section{References}

Benner, R. and Strom, M.: A critical evaluation of the analytical blank associated with DOC measurements by high-temperature catalytic oxidation, Mar. Chem., 41, 153-160, 1993.

Brussaard, C. P. D.: Optimization of procedures for counting viruses by flow cytometry, Appl. Environ. Microbiol., 70, 15061513, 2004.

Brussaard, C. P. D., Weinbauer, M. G., Winter, C., and Payet, J.: Quantification of aquatic viruses by flow cytometry, in: Manual of Aquatic Viral Ecology., edited by: Suttle, C., Wilhelm, S. W., and Weinbauer, M. G., p. 102, ASLO, 2010.

Capone, D. G. and Knapp, A. N.: Oceanography: A marine nitrogen cycle fix?, Nature, 445, 159-160, 2007.

Danovaro, R., Bongiorni, L., Corinaldesi, C., Giovannelli, D., Damiani, E., Astolfi, P., Greci, L., and Pusceddu, A.: Sunscreens cause coral bleaching by promoting viral infections, Environmental Health Perspectives, 116, 441-447, 2008.

Davies, A., Duineveld, G. C. A., Lavaleye, M. S. S., Bergman, M., van Hareb, H., and Roberts, J. M.: Downwelling and deep-water bottom currents as food supply mechanisms to the cold-water coral Lophelia pertusa (Scleractinia) at the Mingulay Reef Complex, Limnol. Oceanogr., 52, 620-629, 2009. 
Davy, J. E. and Patten, N.: Morphological diversity of virus-like particles within the surface microlayer of scleractinian corals, Aquat. Microb. Ecol., 47, 37-44, 2007.

Davy, S. K., Burchett, S. G., Dale, A. L., Davies, P., Davy, J. E., Muncke, C., Hoegh-Guldberg, O., and Wilson, W. H.: Viruses: agents of coral disease?, Dis. Aquat. Org., 69, 101-110, 2006.

Deutsch, C., Sarmiento, J. L., Sigman, D. M., Gruber, N., and Dunne, J. P.: Spatial coupling of nitrogen inputs and losses in the ocean, Nature, 445, 163-167, 2007.

Dinsdale, E. A., Pantos, O., Smriga, S., Edwards, R. A., Angly, F., Wegley, L., Hatay, M., Hall, D., Brown, E., Haynes, M., Krause, L., Sala, E., Sandin, S. A., Thurber, R. V., Willis, B. L., Azam, F., Knowlton, N., and Rohwer, F.: Microbial ecology of four coral atolls in the Northern Line Islands, PLoS ONE, 3, e1584, 2008.

Ducklow, H. W. and Mitchell, R.: Bacterial populations and adaptations in the mucus layer on living corals, Limnol. Oceanogr., 24, 715-725, 1979a.

Ducklow, H. W. and Mitchell, R.: Composition of mucus released by coral reef coelenterates, Limnol. Oceanogr., 24, 706-714, 1979b.

Efrony, R., Loya, Y., Bacharach, E., and Rosenberg, E.: Phage therapy of coral disease, Coral Reefs, 26, 7-13, 2007.

Ferrier-Pagès, C., Leclerq, N., Jaubert, J., and Pelegri, S.: Enhancement of pico- and nanoplankton growth by coral exudates, Aquat. Microb. Ecol., 21, 203-209, 2000.

Gasol, J. M. and del Giorgio, P. A.: Using flow cytometry for counting natural planktonic bacteria and understanding the structure of planktonic bacterial communities, Sci. Mar., 64, 197-224, 2000.

Hadas, E., Marie, D., Shpigel, M., and Ilan, M.: Virus predation by sponges is a new nutrient-flow pathway in coral reef food webs, Limnol. Oceanogr., 51, 1548-1550, 2006.

Hansson, L., Agis, M., Maier, C., and Weinbauer, M. G.: Community composition of bacteria associated with cold-water coral Madrepora oculata: within and between colony variability, Mar. Ecol. Prog. Ser., 397, 89-102, 2009.

Herfort, L., Schouten, S., Abbas, B., Veldhuis, M. J., Coolen, M. J., Wuchter, C., Boon, J. P., Herndl, G. J., and Sinninghe Damste, J. S.: Variations in spatial and temporal distribution of Archaea in the North Sea in relation to environmental variables, FEMS Microbiol. Ecol., 62, 242-257, 2007.

Herndl, G. J. and Velimirov, B.: Microheterotrophic utilization of mucus released by the Mediterranean coral Cladocora cespitosa, Mar. Biol., 90, 363-369, 1986.

Houlebrèque, F., Tambutté, E., Richard, C., and Ferrier-Pagès, C.: Importance of a micro-diet for scleractinian corals, Mar. Ecol. Prog. Ser., 282, 151-160, 2004.

Jensen, S., Neufeld, J. D., Birkeland, N. K., Hovland, M., and Murrell, J. C.: Methane assimilation and trophic interactions with marine Methylomicrobium in deep-water coral reef sediment off the coast of Norway, FEMS Microbiol. Ecol., 66, 320330, 2008a.

Jensen, S., Neufeld, J. D., Birkeland, N.-K., Hoveland, M., and Murrell, J. C.: Insight into the microbial community structure of a Norwegian deep-water coral reef environment, Deep Sea Res. I, 55, 1554-1563, 2008b.

Kellogg, C. A., Lisle, J. T., and Galkiewicz, J. P.: Cultureindependent characterization of bacterial communities associated with the cold-water coral Lophelia pertusa in the northeastern Gulf of Mexico, Appl. Environ. Microbiol., 75, 2294-2303,
2009.

Koren, O. and Rosenberg, E.: Bacteria associated with mucus and tissues of the coral Oculina patagonica in summer and winter, Appl. Environ. Microbiol., 72, 5254-5259, 2006.

Lavaleye, M., Duineveld, G., Lundälv, T., White, M., Guihen, D., Kiriakoulakis, K., and Wolff, G. A.: Coldwater corals on the Tiszler reef, Oceanography, 22, 76-84, 2009.

Maier, C., Hegeman, J., Weinbauer, M. G., and Gattuso, J.-P.: Calcification of the cold-water coral Lophelia pertusa, under ambient and reduced $\mathrm{pH}$, Biogeosciences, 6, 1671-1680, doi:10.5194/bg6-1671-2009, 2009.

Marhaver, K. L., Edwards, R. A., and Rohwer, F.: Viral communities associated with healthy and bleaching corals, Environ. Microbiol., 10, 2277-2286, 2008.

Middelboe, M. and Lyck, P. G.: Regeneration of dissolved organic matter by viral lysis in marine microbial communities, Aquat. Microb. Ecol., 27, 187-194, 2002.

Mortensen, P. B., Hovland, M. T., Fossa, J. H., and Furevik, D. M.: Distribution, abundance and size to seabed characteristics, J. Mar. Biol. Assoc. UK, 81, 581-597, 2001.

Motegi, C., Nagata, T., Miki, T., Weinbauer, M. G., Legendre, L., and Rassoulzadegan, F.: Viral control of bacterial growth efficiency in marine pelagic environments, Limnol. Oceanogr., 54, 1901-1910, 2009.

Murray, A. G. and Jackson, G. A.: Viral dynamics: a model of the effects of size, shape, motion and abundance of single-celled planktonic organisms and other particles, Mar. Ecol. Prog. Ser., 89, 103-116, 1992.

Naumann, M. S., Niggl, W., Laforsch, C., Glaser, C., and Wild, C.: Coral surface area quantification-evaluation of established techniques by comparison with computer tomography, Coral Reefs, 28, 109-117, 2009.

Neulinger, S. C., Jarnegren, J., Ludvigsen, M., Lochte, K., and Dullo, W. C.: Phenotype-specific bacterial communities in the cold-water coral Lophelia pertusa (Scleractinia) and their implications for the coral's nutrition, health, and distribution, Appl. Environ. Microbiol., 74, 7272-7285, 2008.

Parada, V., Herndl, G. J., and Weinbauer, M. G.: Viral burst size of heterotrophic prokaryotes in aquatic systems, J. Mar. Biol. Assoc. UK, 86, 613-621, 2006.

Parada, V., Sintes, E., van Aken, H. M., Weinbauer, M. G., and Herndl, G. J.: Viral abundance, decay and diversity in the mesoand bathypelagic waters of the North Atlantic, Appl. Environ. Microbiol., 73, 4429-4438, 2007.

Patten, N. L., Seymour, J. R., Doubell, M., Waters, R. L., and Mitchell, J. G.: Flow cytometric analysis of virus-like particles and heterotrophic bacteria within coral-associated reef water, J. Mar. Biol. Assoc. UK, 86, 563-566, 2006.

Patten, N. L., Harrison, P. L., and Mitchell, J. G.: Prevalence of virus-like particles within a staghorn scleractinian coral (Acropora muricata) from the Great Barrier Reef, Coral Reefs, 27, 569-580, 2008a.

Patten, N. L., Mitchell, J. G., Middelboe, M., Eyre, B. D., Seuront, L., Harrison, P. L., and Glud, R. N.: Bacterial and viral dynamics during a mass coral spawning period on the Great Barrier Reef, Aquat. Microb. Ecol., 50, 209-220, 2008b.

Paul, J. H., Rose, J. B., Jiang, S. C., Kellogg, C. A., and Dickson, L.: Distribution of viral abundance in the reef environment of Key Largo, Florida, Appl. Environ. Microbiol., 59, 718-724, 1993. 
Peduzzi, P. and Herndl, G. J.: Zooplankton activity fueling the microbial loop: differential growth response of bacteria from oligotrophic and eutrophic waters, Limnol. Oceanogr., 37, 10871092, 1992.

Roberts, J. M., Wheeler, A. J., and Freiwald, A.: Reefs of the Deep: The biology and geology of cold-water coral ecosystems, Science, 312, 543-547, 2006.

Rogers, A. D.: The biology of Lophelia pertusa and other deepwater reef-forming corals and impacts from human activity, Int. Rev. Hydrobiol., 84, 315-406, 1999.

Scheffers, S. R., Bak, R. P. M., and Van Duyl, F. C.: Why is bacterioplankton growth in coral reef framework cavities enhanced?, Mar. Ecol. Prog. Ser., 299, 88-99, 2005.

Schiller, C. and Herndl, G. J.: Evidence of enhanced microbial activity in the interstitial space of branched corals: possible implications for coral reef metabolism, Coral Reefs, 7, 179-184, 1989.

Schöttner, S., Hoffmann, F., Wild, C., Rapp, H. T., Boetius, A., and Ramette, A.: Inter- and intra-habitat bacterial diversity associated with cold-water corals, ISMEJ, 3, 756-759, 2009.

Seymour, J. R., Patten, N., Bourne, D. G., and Mitchell, J. G.: Spatial dynamics of virus-like particles and heterotrophic bacteria within a shallow coral reef system, Mar. Ecol. Prog. Ser., 288, $1-8,2005$.

Sorokin, Y. I.: On the feeding of some scleractinian corals with bacteria and dissolved organic matter, Limnol. Oceanogr., 18, 380-385, 1973.

Suttle, C. A.: Viruses in the sea, Nature, 437, 356-361, 2005.

Van Duyl, F. C., Scheffers, S. R., Thomas, F. I. M., and Driscoll, M.: The effect of water exchange on bacterioplankton depletion and inorganic nutrient dynamics in coral reef cavities, Coral Reefs, 25, 23-36, 2006. van Duyl, F. C., Hegeman, J., Hoogstraten, A., and Maier, C.: Dissolved carbon fixation by sponge-microbe consortia of deep water coral mounds in the NE Atlantic Ocean, Mar. Ecol. Prog. Ser., 358, 137-150, 2008.

Weinbauer, M. G., Arrieta, J. M., Griebler, C., and Herndl, G. J.: Enhanced viral production and infection of bacterioplankton during an iron-induced phytoplankton bloom in the Southern Ocean, Limnol. Oceanogr., 54, 774-784, 2009.

Weinbauer, M. G., Kerros, M.-E., Motegi, C., Wilhartitz, I. C., Rassoulzadegan, F., Torréton, J.-P., and Mari, X.: Bacterial community composition and potential controlling mechanisms along a trophic gradient in a barrier reef system, Aquat. Microb. Ecol., 60, 15-28, 2010.

Wild, C., Huettel, M., Klueter, A., Kremb, S. G., Rasheed, M. Y., and Jorgensen, B. B.: Coral mucus functions as an energy carrier and particle trap in the reef ecosystem, Nature, 428, 66-70, 2004.

Wild, C., Mayr, C., Wehrmann, L., Schöttner, S., Naumann, M., Hoffmann, F., and Rapp, H. T.: Organic matter release by cold water corals and its implication for fauna-microbe interactions, Mar. Ecol. Prog. Ser., 372, 67-75, 2008.

Wild, C., Wehrmann, L. M., Mayr, C., Schöttner, S. I., Allers, E., and Lundälv, T.: Microbial degradation of cold-water coralderived organic matter: potential implication for organic $\mathrm{C}$ cycling in the water column above Tisler Reef, Aquat. Biol., 372, 65-75, 2009.

Wilson, J. W., Dale, A. L., Davy, J. E., and Davy, S. K.: An enemy within? Observations of virus-like particles in reef corals, Coral Reefs, 24, 145-148, 2005.

Yakimov, M. M., Cappello, S., Crisafi, E., Tursi, A., Savani, A., Corselli, C., Scarfi, S., and Giuliano, L.: Phylogenetic survey of metabolically active microbial communities associated with the deep-sea coral Lophelia pertusa from the Apulian plateau, central Mediterranean Sea, Deep Sea Res. I, 53, 62-75, 2006. 